\title{
ChemComm
}

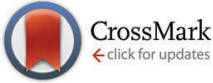

Cite this: Chem. Commun., 2016, 52,7344

Received 19th February 2016, Accepted 13th May 2016

DOI: $10.1039 / c 6 c c 01517 d$

www.rsc.org/chemcomm

\section{Fluorescent liquid pyrene derivative-in-water microemulsions $\dagger$}

\author{
M. J. Hollamby, ${ }^{* a}$ A. E. Danks, ${ }^{\text {b }}$ Z. Schnepp, ${ }^{\text {b }}$ S. E. Rogers, ${ }^{c}$ S. R. Hart ${ }^{d}$ and \\ T. Nakanishi ${ }^{\mathrm{e}}$
}

\begin{abstract}
A fluorescent liquid pyrene derivative with a high fluorescence quantum yield $(65 \%)$ in the bulk state is reported. With this as the sole oil phase, stable luminescent oil-in-water microemulsions have been prepared. Increasing the loading of liquid pyrene swells the droplets, as detected by small-angle neutron scattering. These larger droplets have a greater proportion of pyrene excimer emission contribution in their photoluminescence spectra, which leads to a red shift in the chromaticity of the emission.
\end{abstract}

Attaching branched alkyl chains to $\pi$-conjugated molecules can yield a liquid state at room temperature. ${ }^{1,2}$ The added bulky, flexible groups naturally reduce the solidification temperature, but also disrupt the ability of the $\pi$-conjugated cores to pack via $\pi-\pi$ interactions. The resulting non-volatile functional organic liquids (FOLs), including liquid pyrene derivatives, ${ }^{3-6}$ are being studied for their unique luminescence properties ${ }^{7,8}$ and potential in organic electronic ${ }^{3-6,9,10}$ applications. Advantages include ease of application, ability to form a continuous layer, ability to accommodate dopant molecules, and high thermal and photostability.

One unexplored advantage of luminescent FOLs might be the ability to directly disperse the liquid in a second phase to form an emulsion. Luminescent dyes are often dispersed into micelles, vesicles or oil-in-water nano-emulsion droplets, to act as sensors ${ }^{11}$ or contrast agents ${ }^{12,13}$ for biomedical imaging. However, in those cases the luminescent properties can be limited by the

\footnotetext{
${ }^{a}$ School of Physical and Geographical Sciences, Keele University, Keele, Staffordshire, ST55BG, UK. E-mail: m.hollamby@keele.ac.uk; Tel: $+44(0) 1782733532$

${ }^{b}$ School of Chemistry, University of Birmingham, B15 2TT, UK

${ }^{c}$ ISIS-STFC, Rutherford Appleton Laboratory, Chilton, Oxon OX11 OQX, UK

${ }^{d}$ Institute for Science and Technology in Medicine, Keele University, Keele, Staffordshire, ST55BG, UK

${ }^{e}$ International Center for Materials Nanoarchitectonics, National Institute for Materials Science, 1-2-1 Sengen, Tsukuba 305-0047, Japan

$\dagger$ Electronic supplementary information (ESI) available: Experimental including synthesis of derivative 1. Details on small-angle neutron scattering measurements and model fitting, including parameter tables. See DOI: 10.1039/c6cc01517d
}

concentration of (solid) dye that can be dissolved into an oil phase without self-quenching. ${ }^{12,14}$ The use of FOLs as the sole oil phase may have a distinct advantage, as they often retain significant luminescence in the liquid state. ${ }^{7,8}$

One way to disperse FOLs in water might be to prepare FOL-inwater $(\mathrm{o} / \mathrm{w})$ microemulsions. Microemulsions typically comprise nano-sized oil droplets, form spontaneously on mixing, are thermodynamically stable ${ }^{15}$ and are consequently commonly investigated as a means to deliver hydrophobic drugs. ${ }^{16}$ As no other oil is required, a FOL/w microemulsion has the potential to achieve a dye loading of $>35 \%$ within the droplet cores, based on the relative mass of the fluorescent $\pi$-conjugated moiety versus the attached alkyl chains. Luminescent FOL/w microemulsions therefore have potential in sensing or imaging applications, provided that the luminescence properties of the FOL can be retained upon compartmentalisation into a nano-sized droplet.

Here, a new liquid pyrene derivative $\mathbf{1}$ (Fig. 1a) is reported, which has a high photoluminescence quantum yield in the bulk liquid state. Stable $1 / \mathrm{C}_{12} \mathrm{E}_{6} /$ water microemulsions are prepared for the first time, stabilised by the non-ionic surfactant hexaethylene glycol monododecyl ether, $\mathrm{C}_{12} \mathrm{E}_{6}$. $\mathrm{C}_{12} \mathrm{E}_{6}$ was chosen as it is known to readily stabilise $\mathrm{o} / \mathrm{w}$ microemulsions without the need for a co-surfactant. ${ }^{17,18}$ The effect of the concentrations of $\mathbf{1}$ and $\mathrm{C}_{12} \mathrm{E}_{6}$ on the droplet size, and the photoluminescence of the microemulsions is investigated.

Derivative 1 (Fig. 1a) was synthesised as described in the ESI. $\dagger$ Under normal light, $\mathbf{1}$ is a yellow oil, but under UV light $(\lambda=365 \mathrm{~nm})$ an intense blue-green emission is observed (Fig. 1b and c). UV-visible absorption spectra of pyrene and $\mathbf{1}$ in solution (solvent $=\mathrm{CH}_{2} \mathrm{Cl}_{2},[1]=10^{-5} \mathrm{M}$ ) and of $\mathbf{1}$ as a liquid film are shown in Fig. 1d. The absorption spectra of the two solutions exhibit similar features, with several sharp maxima in the detected range. The maxima of $\mathbf{1}$ are red-shifted in comparison to pyrene, suggesting a narrowing of the HOMO-LUMO band gap. ${ }^{19}$ Broader peaks, further red-shifted in comparison to the solution state spectra, are observed in the absorption data for the film of $\mathbf{1}$. This may indicate an increased proximity of the pyrene moieties within the film. ${ }^{20}$ 
a)

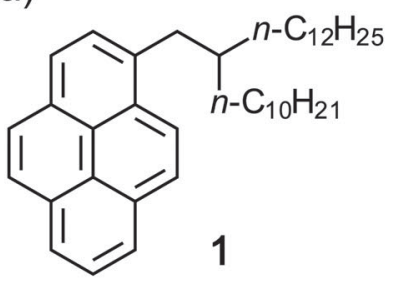

.

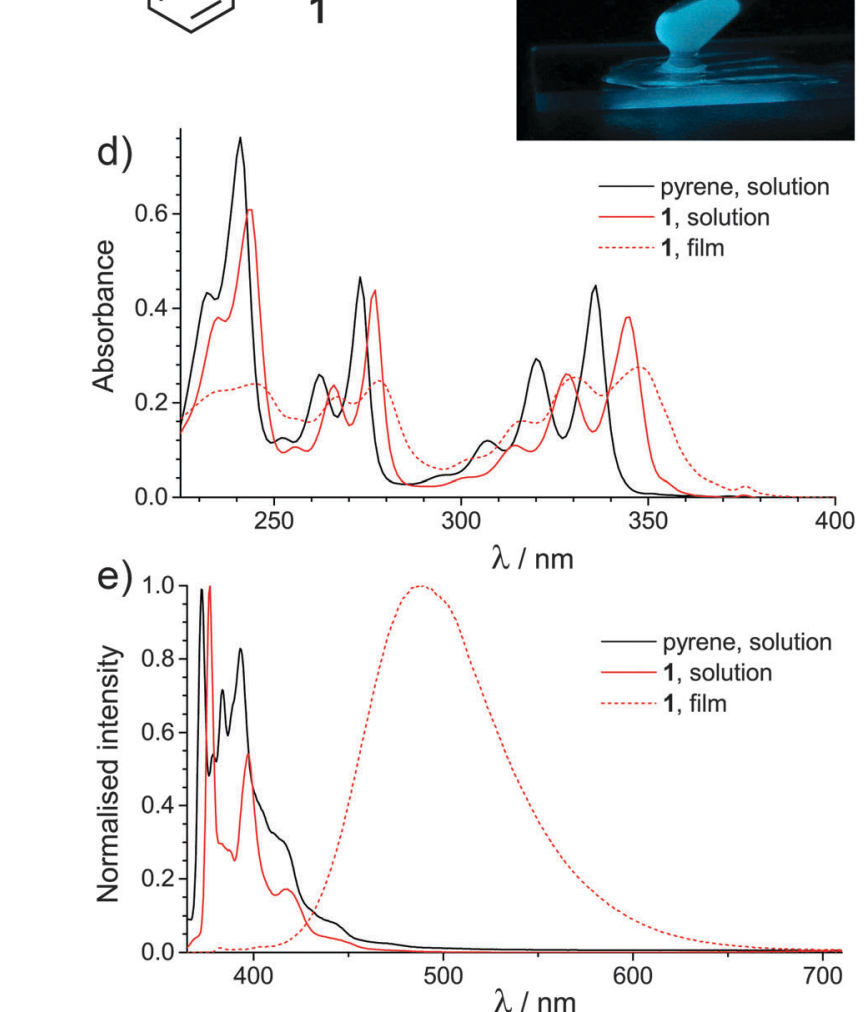

Fig. 1 (a) Structure of 1 . (b) Photograph of 1, taken under normal light conditions. (c) Photograph of 1, taken under UV light $(\lambda=365 \mathrm{~nm})$, showing the bright excimer emission, with a quantum yield of around $65 \%$. (d) UV-visible absorption spectra of 1 in the solution and bulk film state, with that for pyrene solution provided for comparison. (e) Normalised photoluminescence emission spectra of pyrene $\left(10^{-5} \mathrm{M}\right)$ and $1\left(10^{-5} \mathrm{M}\right)$ in solution in $\mathrm{CH}_{2} \mathrm{Cl}_{2}$ and of 1 in the bulk film state at $25^{\circ} \mathrm{C}$.

The normalised photoluminescence (PL) spectra of $\mathbf{1}$ and pyrene in solution (in $\mathrm{CH}_{2} \mathrm{Cl}_{2},[\mathbf{1}]=10^{-5} \mathrm{M}$ ) and $\mathbf{1}$ as a liquid film are shown in Fig. 1e. The PL data for the solutions are characteristic of pyrene monomer emission $\left(\lambda_{\mathrm{em}} \approx 350-450 \mathrm{~nm}\right)$. A red-shift is again noted in the maxima of $1 \mathrm{vs}$. pyrene, alongside a reduction in the fine structure of the spectrum, in line with previous work on mono-substituted pyrenes. ${ }^{19}$ The PL quantum yields $\left(\Phi_{\mathrm{F}}\right)$ of the solutions of pyrene and 1 in $\mathrm{CH}_{2} \mathrm{Cl}_{2}$ were 0.06 and $0.13( \pm 0.01)$ respectively at $25^{\circ} \mathrm{C}$. The increase in $\Phi_{\mathrm{F}}$ for $1 \mathrm{vs}$. pyrene is due to $\pi-\sigma$ conjugation. ${ }^{19}$ The $\Phi_{\mathrm{F}}$ values are lower than $\Phi_{\mathrm{F}}=0.28$ (pyrene) and 0.41 (1-butylpyrene). ${ }^{19}$ However, in that work, deaerated solutions were used; the oxygen in air is known to quench pyrene PL. ${ }^{21}$

The PL data for the film of $\mathbf{1}$ is dominated by an intense excimer emission $\left(\lambda_{\mathrm{em}} \approx 400-650 \mathrm{~nm}\right){ }^{22}$ A CIE xy chromaticity diagram for both the solution and film state of 1 is shown in Fig. S1 (ESI $\dagger$ ). At $25{ }^{\circ} \mathrm{C}$ in air, $\Phi_{\mathrm{F}}=0.65( \pm 0.01)$ was obtained, representing a
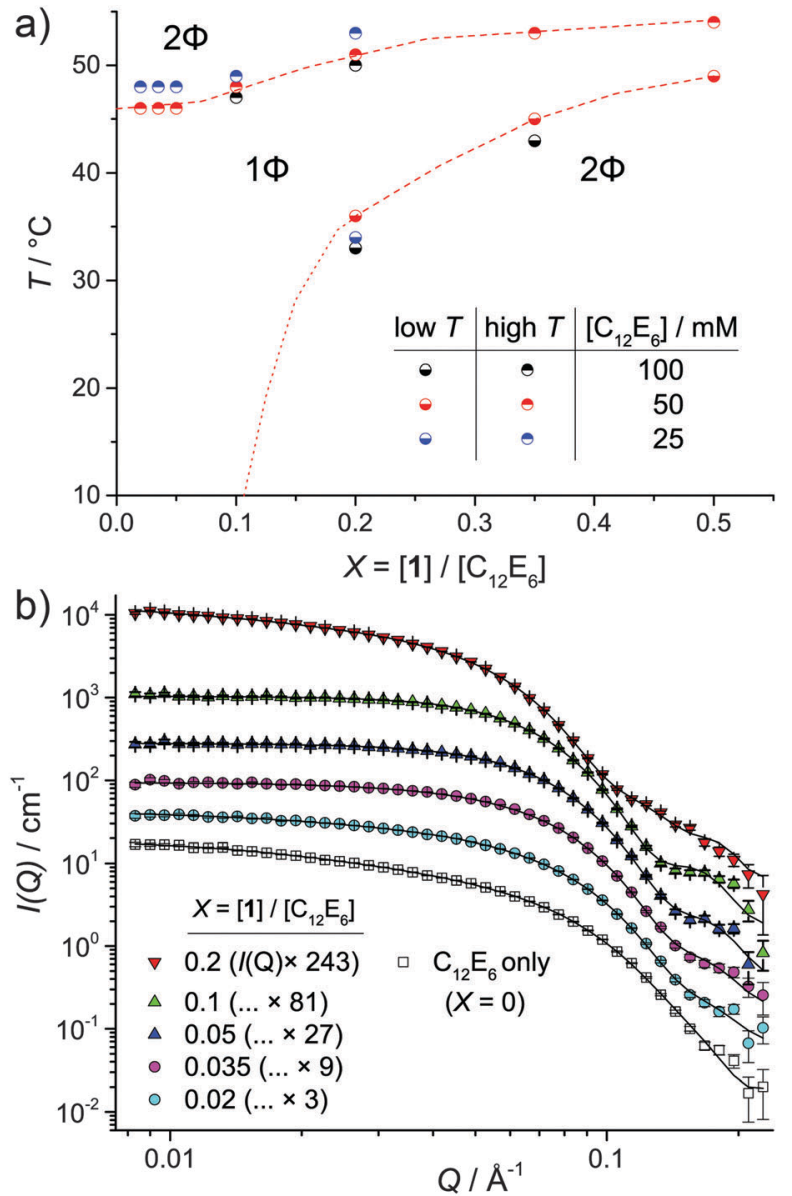

Fig. 2 (a) Phase behaviour of the $1 / C_{12} E_{6} / D_{2} O$ microemulsions as a function of temperature, $X$ and $\left[\mathrm{C}_{12} \mathrm{E}_{6}\right]$. Regions representing a single phase microemulsion $(1 \Phi)$ and two-phase system $(2 \Phi)$ are divided by a dashed (---) line where the position of the boundary is known and (...) where it has been approximated. (b) SANS data for $1 / C_{12} E_{6} / D_{2} O$ microemulsions $\left(\left[\mathrm{C}_{12} \mathrm{E}_{6}\right]=50 \mathrm{mM}\right)$. Data were measured at $25^{\circ} \mathrm{C}$ in all cases except for $X=0.2$, which was measured at $45^{\circ} \mathrm{C}$. For clarity, the datasets are each scaled by a constant factor, as detailed in the legend. Lines represent fits using a cylindrical $P(Q)$, with $S(Q)$ as described in the text.

significant enhancement in PL intensity $v s$. the solution state. High PL $\Phi_{\mathrm{F}}$ have been found for other FOLs, including those based on anthracene $\left(\Phi_{\mathrm{F}}=0.55\right)^{7}$ and oligo( $p$-phenylenevinylene) $\left(\Phi_{\mathrm{F}}=\right.$ $0.48),{ }^{8}$ although in those cases the solution state $\Phi_{\mathrm{F}}$ was higher. Here, the enhancement is likely to originate from two factors: In the liquid state, the pyrene sections of $\mathbf{1}$ may be sufficiently close to form a highly emissive excimer state, but not so closely packed for self-quenching. Secondly, air penetration into the more viscous liquid 1 will be slower than into $\mathrm{CH}_{2} \mathrm{Cl}_{2}$, again reducing quenching.

Microemulsions were prepared in water $\left(\mathrm{D}_{2} \mathrm{O}\right)$, comprising varying concentrations of the surfactant $\mathrm{C}_{12} \mathrm{E}_{6}$ and 1 . The temperature-dependant phase behaviour is shown in Fig. 2a. In line with other work on o/w microemulsions, ${ }^{23,24}$ changing the oil/surfactant ratio $X=[1] /\left[\mathrm{C}_{12} \mathrm{E}_{6}\right]$ significantly alters the phase behaviour, while altering $\left[\mathrm{C}_{12} \mathrm{E}_{6}\right]$ at constant $X$ yields only minor shifts in the phase boundaries. For $0<X<0.1$, single-phase microemulsions were observed within the range $10-46{ }^{\circ} \mathrm{C}$. 
Outside the single phase region ( $1 \Phi$ on Fig. $2 \mathrm{a}$ ), the samples became cloudy and separated into oil-rich and water-rich layers $(2 \Phi)$. Single-phase microemulsions were observed up to $X=0.5$, albeit over a much reduced $T$-range.

Small-angle neutron scattering, SANS probed the droplet structure of the $1 / \mathrm{C}_{12} \mathrm{E}_{6}$ /water microemulsions (Fig. 2b). SANS contains information on the size distribution and shape of the droplets via the form factor $P(Q)$, and on how droplets interact via the structure factor $S(Q)$. These contributions are scaled by concentration and the difference $\Delta \rho$ between the scattering length density of the droplets and the solvent medium. The latter is maximised here by detecting ${ }^{1} \mathrm{H}$-rich droplets in $\mathrm{D}_{2} \mathrm{O}$.

SANS data for $1 / \mathrm{C}_{12} \mathrm{E}_{6} / \mathrm{D}_{2} \mathrm{O}$ microemulsions for $X=0-0.2$ are shown in Fig. $2 \mathrm{~b}$. All data was collected in the single-phase region $\left(25{ }^{\circ} \mathrm{C}\right.$ for $X=0-0.1,45{ }^{\circ} \mathrm{C}$ for $X=0.2$ ). The profiles are typical of SANS from non-ionic surfactant micelles ${ }^{25-28}$ or microemulsion droplets. ${ }^{18}$ When stabilised by $\mathrm{C}_{12} \mathrm{E}_{6},{ }^{17,25,29}$ or the closely-related $\mathrm{C}_{12} \mathrm{E}_{5},{ }^{18,28,30,31}$ such assemblies are thought to be elongated. However, the droplet aspect ratio tends to decrease with the inclusion of greater amounts of oil. ${ }^{17}$ Consequently, a SchultzZimm ${ }^{32,33}$ distribution of solid cylinders (see ESI $\dagger$ for details) was used as the $P(Q) \cdot{ }^{34}$ A full report of the fit parameters and the significant values calculated from them are given in ESI, $\dagger$ Tables $\mathrm{S} 1$ and $\mathrm{S} 2$. The latter includes (i) the number of $\mathrm{C}_{12} \mathrm{E}_{6}$ and 1 molecules per micelle $\left(N_{\text {surf }}\right.$ and $\left.N_{1}\right)$, (ii) the interfacial area occupied by $\mathrm{C}_{12} \mathrm{E}_{6},\left(a_{\mathrm{h}}\right.$ and $\left.a_{\mathrm{h}, \mathrm{IF}}\right)$, and (iii) the number of molecules in the system approximated by fitting, divided by the number of molecules known to be present, $n_{\text {fit }} / n_{\text {calc }}$. In almost all cases, both the goodness-of-fit parameter, $\chi^{2}$ and $n_{\text {fit }} / n_{\text {calc }}$ are around 1, indicating that the fits agree with the data within error and that the parameters adopt reasonable values.

In addition to the $P(Q)$, for $X=0$ and 0.02 , an attractive Orstein-Zernicke $S(Q)$ was required to account for additional scattering at low $Q .{ }^{26,28}$ The parameter $\kappa$ indicates the strength of these interactions and noticeably reduces upon uptake of $\mathbf{1}$ $(\kappa=1.0$ and 0.2 for $X=0$ and 0.02 respectively - see Table S1, ESI $\dagger$ ). Apparent attractive interactions are likely to be coupled to increased length or a flexible (e.g. end-on-end cluster formation). ${ }^{28}$ A reduction in $\kappa$ points to a reduced tendency of the system to form clusters upon uptake of 1 . After $X=0.035$, to $X=0.1$ a repulsive effective hard sphere $S(Q)$ gave better fits to the data, which suggests a change from clustered or wormlike assemblies to discrete microemulsion droplets. Similar transitions with increased oil incorporation into o/w microemulsion droplets have previously been noted. ${ }^{30}$

For $X=0.2$, increased scattering at low $Q$ is again observed, requiring a shift back to an attractive Orstein-Zernicke $S(Q)$. However, rather than indicating micelle elongation, these apparent attractions may be indicative of critical concentration fluctuations, due to the proximity of the measurement temperature to the phase boundary (Fig. 2).

Selected results for $\left[\mathrm{C}_{12} \mathrm{E}_{6}\right]=50 \mathrm{mM}$ are shown in Table 1 . As 1 is added to the $\mathrm{C}_{12} \mathrm{E}_{6} / \mathrm{D}_{2} \mathrm{O}$ solution, the droplet length, $L$ and aspect ratio, $L / 2 R$ both drop, in line with previous results. ${ }^{17}$ After this, increasing the number of molecules of 1 per micelle $\left(N_{\mathbf{1}}\right)$ leads to increases in $L$ and the radius, $R$ at an approximately
Table 1 Selected analysis results arising from SANS fitting for $1 / C_{12} E_{6} /$ water microemulsions, using a cylindrical $P(Q)$ and $S(Q)$ as described in the text

\begin{tabular}{lllllll}
\hline$X$ & $T /{ }^{\circ} \mathrm{C}$ & $R / \AA$ & $\sigma$ & $L / \AA$ & $L / 2 R$ & $N_{\mathbf{1}} /$ micelle \\
\hline 0 & 25 & 21 & 0.11 & 64 & 1.5 & 0 \\
0.02 & 25 & 23 & 0.14 & 61 & 1.3 & 3 \\
0.035 & 25 & 25 & 0.11 & 66 & 1.3 & 6 \\
0.05 & 25 & 25 & 0.11 & 64 & 1.3 & 9 \\
0.1 & 25 & 28 & 0.08 & 70 & 1.3 & 22 \\
0.2 & 45 & 33 & 0.16 & 86 & 1.3 & 75
\end{tabular}

constant aspect ratio, $L / 2 R$ and distribution width, $\sigma$. The swelling requires a larger $N_{\text {surf }}$ to maintain the interface, as the approximate interfacial area occupied by $\mathrm{C}_{12} \mathrm{E}_{6}, a_{\mathrm{h}}$ - calculated as the droplet surface area divided by $N_{\text {surf }}$ - remains relatively constant at around $85 \AA^{2}$ in all cases (Table S2, ESI $\dagger$ ). This value of $a_{\mathrm{h}}$ is larger than previously reported for $\mathrm{C}_{12} \mathrm{E}_{6}$ at the air-liquid interface $\left(55 \AA^{2}\right),{ }^{35}$ or in bi-continuous systems $\left(69 \AA^{2}\right) .{ }^{36}$ However, its calculation assumes a sharp oil-water interface at the edge of the micelles. Moving the position of the interface $3 \AA$ towards the micelle centre, which is reasonable as the extended length of the $\mathrm{C}_{12} \mathrm{E}_{6}$ headgroup is $10.7 \AA{ }^{35}$ yields values $\left(a_{\mathrm{h}, \mathrm{IF}}\right.$ in Table S2, ESI $\left.\dagger\right)$ of around $70 \AA^{2}$.

The photoluminescence, PL spectra of the $1 / \mathrm{C}_{12} \mathrm{E}_{6} / \mathrm{D}_{2} \mathrm{O}$ microemulsions are shown in Fig. 3a. Despite incorporation into microemulsion droplets, the bright luminescence of $\mathbf{1}$ is retained. However, the relative intensity of the excimer (broad peak, $\lambda_{\mathrm{em}} \approx$ 400-650 $\mathrm{nm}$ ) emission increases with increasing $X$. Size and shape dependent emission is common in inorganic quantum $\operatorname{dots}^{37}$ and has been demonstrated in organic nanocrystals. ${ }^{38}$ In this case, the change in excimer/monomer emission ratio, shown inset on Fig. 3a as $I_{477 n m} / I_{377 n m}$, is likely to stem from the relative proximity of molecules of $\mathbf{1}$. This can be understood by considering the solubility of the pyrene moiety of $\mathbf{1}$ within the alkyl region. The maximum solubility of pyrene in $n$-hexane and $n$-octane, in mole fraction, is 0.00857 and 0.01372 respectively. ${ }^{39}$ Assuming a linear dependency with chain length, the solubility of pyrene in the alkyl region of the micelles of $\mathrm{C}_{12} \mathrm{E}_{6}$ is approximately 0.025 (in mole fraction). Therefore, at $X=0.02$, the molecules of 1 can mostly be solubilised into the alkyl region of the micelles and are therefore mobile, as depicted in Fig. 3b. Their lower proximity reduces the potential for excimer formation. As $X$ increases, the solvophobicity of the pyrene moiety is likely to drive the formation of a 1-rich region within the microemulsion droplets, as depicted in Fig. $3 \mathrm{~b}$ for $X=0.1$. The presence of such a region explains the increased excimer emission signal, as the molecules of $\mathbf{1}$ are held closer together, facilitating excimer formation. Similar solvophobicity-driven assembly has already been noted for $\mathrm{C}_{60}$-derivatives in $n$-alkane solvents. ${ }^{40}$

In conclusion, stable o/w microemulsions have been prepared with a brightly luminescent organic functional liquid pyrene $\mathbf{1}$ as the sole oil phase. Small-angle scattering has confirmed the nanoscale structure of the approximately cylindrical microemulsion droplets, which behave as discrete hard spheres at intermediate oil loading. The microemulsions are luminescent, with an emission chromaticity that can be tuned by droplet size. 


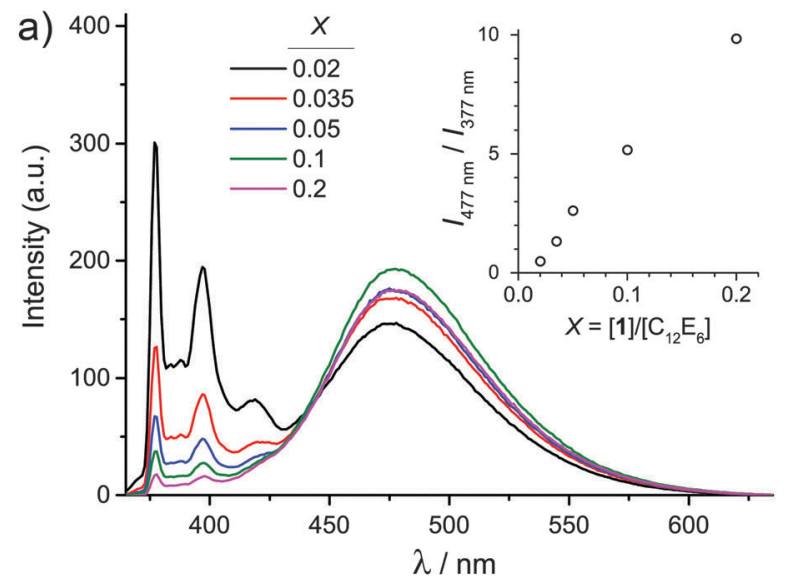

b) $\quad X=0.02$

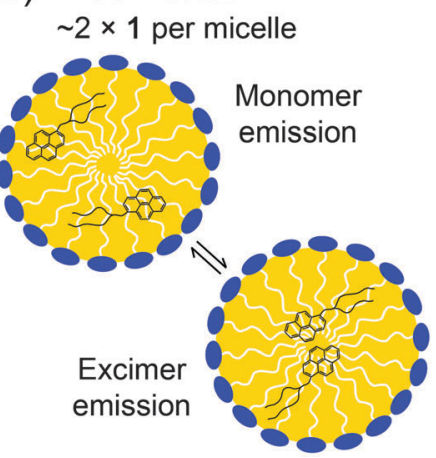

$X=0.1$ $\sim 20 \times 1$ per micelle

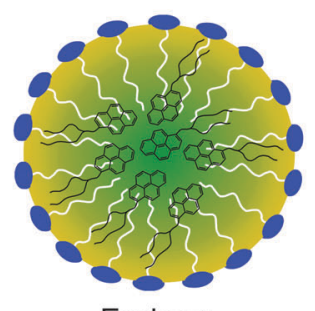

Excimer emission

Fig. 3 (a) Photoluminescence, $\mathrm{PL}$ spectra for $1 / \mathrm{C}_{12} \mathrm{E}_{6} / \mathrm{D}_{2} \mathrm{O}$ microemulsions at different values of $X\left(\left[\mathrm{C}_{12} \mathrm{E}_{6}\right]=50 \mathrm{mM}\right)$. All spectra were collected in the single phase region ( $1 \Phi$ on Fig. 1a). (inset, a) Plot of relative PL intensity at $477 \mathrm{~nm}$ and $377 \mathrm{~nm}$ as a function of $X$. (b) Idealised depiction of the changes that take place within the microemulsion droplets as $X$ increases, based on the PL results, as explained in the text.

They therefore have the potential to be used in sensing or imaging applications: Future work will explore those possibilities.

MH thanks the Royal Society for provision of Research Grant RG140500 to support this project. AD thanks the University of Birmingham for his PhD studentship. STFC is acknowledged for the allocation of beam time, consumables and travel.

\section{Notes and references}

1 M. J. Hollamby and T. Nakanishi, J. Mater. Chem. C, 2013, 1, 6178-6183.

2 S. S. Babu and T. Nakanishi, Chem. Commun., 2013, 49, 9373-9382.

3 T. Kasahara, S. Matsunami, T. Edura, J. Oshima, C. Adachi, S. Shoji and J. Mizuno, Sens. Actuators, A, 2013, 195, 219-223.

4 M. Tsuwaki, T. Kasahara, T. Edura, S. Matsunami, J. Oshima, S. Shoji, C. Adachi and J. Mizuno, Sens. Actuators, A, 2014, 216, 231-236.

5 T. Kasahara, S. Matsunami, T. Edura, R. Ishimatsu, J. Oshima, M. Tsuwaki, T. Imato, S. Shoji, C. Adachi and J. Mizuno, Sens. Actuators, B, 2015, 207(part A), 481-489.

6 N. Kobayashi, T. Kasahara, T. Edura, J. Oshima, R. Ishimatsu, M. Tsuwaki, T. Imato, S. Shoji and J. Mizuno, Sci. Rep., 2015, 5, 14822.

7 S. S. Babu, M. J. Hollamby, J. Aimi, H. Ozawa, A. Saeki, S. Seki, K. Kobayashi, K. Hagiwara, M. Yoshizawa, H. Möhwald and T. Nakanishi, Nat. Commun., 2013, 4, 1969.

8 S. S. Babu, J. Aimi, H. Ozawa, N. Shirahata, A. Saeki, S. Seki, A. Ajayaghosh, H. Möhwald and T. Nakanishi, Angew. Chem., Int. Ed., 2012, 51, 3391-3395.

9 S. Hirata, K. Kubota, H. H. Jung, O. Hirata, K. Goushi, M. Yahiro and C. Adachi, Adv. Mater., 2011, 23, 889-893.

10 T. G. Plint, B. A. Kamino and T. P. Bender, J. Phys. Chem. C, 2015, 119, 1676-1682.

11 Y. Yuan, H. Peng, J. Ping, X. Wang, F. You, Y. Yuan, H. Peng, J. Ping, X. Wang and F. You, BioMed Res. Int., 2015, 2015, 245031.

12 A. S. Klymchenko, E. Roger, N. Anton, H. Anton, I. Shulov, J. Vermot, Y. Mely and T. F. Vandamme, RSC Adv., 2012, 2, 11876-11886.

13 J. F. Lovell, C. S. Jin, E. Huynh, H. Jin, C. Kim, J. L. Rubinstein, W. C. W. Chan, W. Cao, L. V. Wang and G. Zheng, Nat. Mater., 2011, 10, 324-332.

14 A. Wagh, S. Y. Qian and B. Law, Bioconjugate Chem., 2012, 23, 981-992.

15 D. J. McClements, Soft Matter, 2012, 8, 1719-1729.

16 M. J. Lawrence and G. D. Rees, Adv. Drug Delivery Rev., 2000, 45, 89-121.

17 Y. Einaga, Y. Totake and H. Matsuyama, Polym. J., 2004, 36, 971-978.

18 U. Menge, P. Lang, G. H. Findenegg and P. Strunz, J. Phys. Chem. B, 2003, 107, 1316-1320.

19 Y. Niko, S. Kawauchi, S. Otsu, K. Tokumaru and G. Konishi, J. Org. Chem., 2013, 78, 3196-3207.

20 P. Avis and G. Porter, J. Chem. Soc., Faraday Trans. 2, 1974, 70, 1057-1065.

21 P. Hrdlovič, J. Kollár and Š. Chmela, J. Photochem. Photobiol., A, 2004, 163, 289-296.

22 E. M. S. Castanheira and J. M. G. Martinho, Chem. Phys. Lett., 1991, 185, 319-323.

23 P. D. I. Fletcher and J. S. Morris, Colloids Surf., A, 1995, 98, 147-154.

24 R. Aveyard, B. P. Binks and P. D. I. Fletcher, Langmuir, 1989, 5, 1210-1217.

25 J. Gapiński, J. Szymański, A. Wilk, J. Kohlbrecher, A. Patkowski and R. Hołyst, Langmuir, 2010, 26, 9304-9314.

26 R. Triolo, L. J. Magid, J. S. Johnson and H. R. Child, J. Phys. Chem., 1982, 86, 3689-3695.

27 J. Penfold, E. Staples and I. Tucker, J. Phys. Chem. B, 2002, 106, 8891-8897.

28 M. J. Hollamby, R. Tabor, K. J. Mutch, K. Trickett, J. Eastoe, R. K. Heenan and I. Grillo, Langmuir, 2008, 24, 12235-12240.

29 W. Brown, R. Johnsen, P. Stilbs and B. Lindman, J. Phys. Chem., 1983, 87, 4548-4553.

30 U. Menge, P. Lang and G. H. Findenegg, Colloids Surf., A, 2000, 163, 81-90.

31 U. Menge, P. Lang and G. H. Findenegg, J. Phys. Chem. B, 1999, 103, 5768-5774.

32 G. V. Z. Schulz, J. Phys. Chem., 1939, B43, 25.

33 B. H. Zimm, J. Chem. Phys., 1948, 16, 1099.

34 The method proposed by Gapínski et al. (ref. 26), using an elliptical cylinder for the $P(Q)$ and a rod-like $S(Q)$ was also trialled, but found poor agreement with the data.

35 J. R. Lu, Z. X. Li, R. K. Thomas, E. J. Staples, I. Tucker and J. Penfold, J. Phys. Chem., 1993, 97, 8012-8020.

36 T. Sottmann, R. Strey and S.-H. Chen, J. Chem. Phys., 1997, 106, 6483-6491.

37 A. P. Alivisatos, Science, 1996, 271, 933-937.

38 H.-B. Fu and J.-N. Yao, J. Am. Chem. Soc., 2001, 123, 1434-1439.

39 C. E. Hernández, K. S. Coym, L. E. Roy, J. R. Powell, J. Acree and E. William, J. Chem. Thermodyn., 1998, 30, 37-42.

40 M. J. Hollamby, M. Karny, P. H. H. Bomans, N. A. J. M. Sommerdjik, A. Saeki, S. Seki, H. Minamikawa, I. Grillo, B. R. Pauw, P. Brown, J. Eastoe, H. Möhwald and T. Nakanishi, Nat. Chem., 2014, 6, 690-696. 